\title{
Cloudy central corneal dystrophy of François
}

\section{Five cases in the same family}

\author{
I. M. STRACHAN \\ Department of Ophthalmology, Royal Hospital, West Street, Sheffeld
}

François (1956a) reported eight cases of a corneal dystrophy which had not previous w్j been described. The lesion, visible only with the slit lamp, affected a disc in the centres third of the corneal stroma, and consisted of small cloudy grey areas with indefinif structure and indistinct margins. These areas were larger and more numerous in the posterior part of the stroma and became smaller and less frequent in the anterior para In some cases the anterior layers of the stroma were unaffected but in others the gref patches reached Bowman's membrane. The corneal endothelium and epithelium we $\vec{B}$ unaffected. The ages of his patients ranged from 35 to 76 years. It was not considere⿻ that the dystrophy affected the visual acuity, as in those patients with an acuity of leg than $6 / 6$ there were other ocular lesions to account for the visual impairment. In sibship of five two members were affected, but the other six cases described had no affecteg relatives. The condition was said to be non-progressive and the mode of inheritance w⿳⺈冂大 obscure (François, 1956b; 196r). A further case was described by François and Neeten (1957) in a family with central speckled corneal dystrophy.

Collier ( 1964 ) described a woman of 72 years with central speckled dystrophy in bot eyes and cloudy central dystrophy in one. The daughter of this patient also suffere from central speckled corneal dystrophy. Collier ( 1965 ) described another case in on of two sisters who both suffered from pseudoxanthoma elasticum. The i 7-year-old som of this patient had some fine opacities in the posterior third of the corneal stroma in on: eye. Collier (1966) described a further case in a 77-year-old man whose son was foung to have a predescemetic dystrophy.

\section{Material}

(I) A 77-year-old woman (Fig. I, I, 2) complained of failing vision due to senile cataract, anid was noted to have cloudy central corneal dystrophy which was so marked as to be visible to the naked eye (Fig. 2).

The appearance described by François (1956a) was confirmed by slit-lamp examination. the available members of her family were examined (Fig. I), and this brought to light four mor cases: two daughters (II, 7 and II, IO), a granddaughter (III, I2), and a niece (II, 4).

(2) A woman aged 53 (Case II, 7) had corneal lesions similar to her mother's, which were als visible to the naked eye.

(3) A woman aged 33 (Case II, Io) had less marked corneal involvement confined to the posteriơ layers of the stroma and visible only by the slit lamp. 

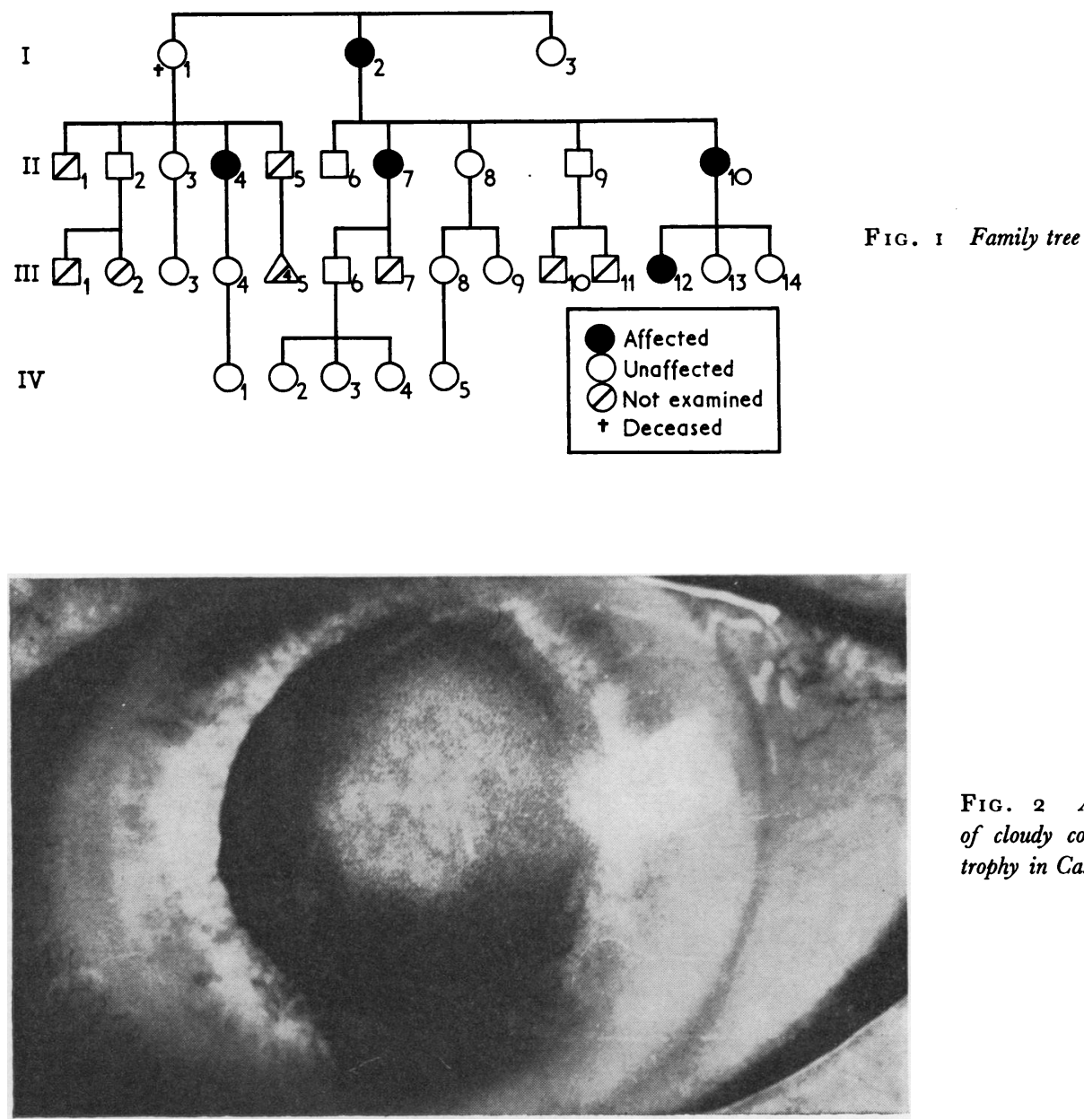

Fig. 2 Appearance of cloudy corneal dystrophy in Case I, 2

(4) An 8-year-old girl (Case III, I2) showed posterior stromal lesions visible by the slit lamp.

(5) A 47-year-old woman (Case II, 4) also had lesions like those of Cases 3 and 4. This case was discovered when members of a collateral branch of the family were examined.

All these five cases had equal involvement of both corneae. Four had visual acuity of $6 / 5$ in each eye and removal of the cataract from the right eye of Case I improved her visual acuity to $6 / 5$ also.

\section{Discussion}

The mode of inheritance of cloudy central corneal dystrophy in the cases previously reported has been uncertain. Only two pairs of related cases of cloudy central dystrophy have been described previously (François, 1956a; Collier, 1965). François's cases were two sibs and Collier's a doubtfully affected son of an affected mother. The family described here showed inheritance of the trait in three successive generations and therefore appears to show a dominant mode of transmission. 


\section{Summary}

Five cases of the cloudy central corneal dystrophy of François in the same family are described; in this family it appears to have been transmitted as a dominant trait.

I wish to acknowledge the secretarial help given by Mrs. M. E. Goodliffe and to thank Mr. F. M. Dunca荡. who took the photograph.

\section{References}

COllier, м. (1964) Bull. Soc. Ophtal. Fr., p. 608

$$
\begin{aligned}
& \text { (1965) Ibid., p. } 30 \mathrm{I} \\
& \text { (1966) Ibid., p. } 575 \\
& \text { FRAnçors, J. (1956a) Bull. Soc. belge Ophtal., No. i I I, p. } 39 \text { I } \\
& \text { (1956b) 7. Génét. hum., 5, I89 } \\
& \text { - (1961) "Heredity in Ophthalmology", p. } 3 \text { 12. Mosby, St. Louis } \\
& \text { and NeEtens, A. (1957) Bull. Soc. belge Ophtal., No. I14, p. } 641
\end{aligned}
$$

